\title{
The CNS and bladder dysfunction
}

\section{Stasa D. Tadic ${ }^{1 *}$, Gert Holstege ${ }^{2}$ and Derek J. Griffiths ${ }^{1}$}

\author{
Addresses: ${ }^{1}$ Division of Geriatric Medicine and Gerontology, University of Pittsburgh, Pittsburgh, PA, USA 15213 ; ${ }^{2}$ University of Groningen, \\ University Medical Center Groningen, Center for Uroneurology, Groningen, The Netherlands \\ * Corresponding author: Stasa D. Tadic (std45@pitt.edu) \\ FI000 Medicine Reports 2012, 4:20 (doi:I0.3410/M4-20) \\ This is an open-access article distributed under the terms of the Creative Commons Attribution-Non Commercial License \\ (http://creativecommons.org/licenses/by-nc/3.0/legalcode), which permits unrestricted use, distribution, and reproduction in any medium, \\ provided the original work is properly cited. You may not use this work for commercial purposes. \\ The electronic version of this article is the complete one and can be found at: http://f1000.com/reports/m/4/20
}

\begin{abstract}
The brain's role in the development and maintenance of bladder control is critical, although its precise role in patient-reported complaints such as urgency and urine leakage is unknown. Functional brain imaging studies have advanced our knowledge of brain activity during the micturition cycle, showing multiple neuronal circuits involved as parts of a 'brain-bladder control network.' Yet, new advances need to be made in order to incorporate this knowledge into existing models of neuroanatomy and of clinical syndromes of bladder dysfunction and related clinical practice. This short article explains why and how brain imaging methods are poised to achieve that goal and decode the role of the brain in widely prevalent clinical conditions related to bladder dysfunction.
\end{abstract}

\section{Introduction}

To become a member of society, besides learning language or how to walk, a child needs to learn to control the bladder. This skill enables the child to adapt to the social environment and void or postpone voiding voluntarily, regardless of the strength of the bladder sensation. It requires the voiding reflex, stemming from the bladder, to be integrated with, and modulated by, a network of centers in the cerebral cortex that are believed to process all relevant information and promote or inhibit voiding accordingly. Thus the brain is a necessary part of bladder control [1]. If a pathogenic factor such as brain injury or stroke affects it, control may be lost, presenting as involuntary urine leakage - the symptom of urinary incontinence [2]. Sometimes with these patients, loss of urine is preceded by urgency, a sudden, compelling desire to void that is difficult to defer and is accompanied by fear of leakage $[2,3]$. However, patients like this are not typical of day-to-day urological practice [4]. Most patients who complain of urgency, with or without urine leakage, have no obvious brain abnormality. The bladder also appears normal, but if tested by continuous fast filling during routine urodynamics it may occasionally show an involuntary contraction of the bladder muscle (and relaxation of the sphincter), which may cause leakage.
Known as detrusor overactivity [2], this phenomenon represents the only unambiguous physiological sign that bladder control is impaired in this seemingly idiopathic condition. Although it seems obvious that the CNS is involved, the observation of detrusor overactivity during a bladder examination has de facto defined the entire clinical and research approach to urgency and incontinence (including the so-called "overactive bladder" syndrome) [4]. The consequence of this approach - to diagnose the problem by investigating the bladder and treat it as if it were only a bladder condition - is that no current therapy is highly satisfactory or curative $[5,6]$.

Is the function of the brain relevant in patients with "overactive bladder" manifested by urgency with or without incontinence? One piece of evidence is that bladder symptoms can be improved without altering the bladder itself. In simple terms, if we teach subjects how to confront urgency by utilizing an urge suppression strategy, at least half of the urgency and leakage episodes disappear [7]. The fact that a change in brain activity improves bladder symptoms suggests that the CNS is a causative factor. This leads to a further question - are urgency and urinary incontinence caused by the brain, bladder or both? Decoding the role of the brain in this idiopathic 
yet widely prevalent clinical condition remains a major unsolved $21^{\text {st }}$-century urological mystery. Below, we explain why brain studies are important and how brain imaging methods are poised to solve the mystery.

\section{Recent advances}

Since the last decade of the $20^{\text {th }}$ century, functional imaging of regional activity in the brain's gray matter has revealed characteristic changes during bladder voiding and storage and, more recently, during patient-reported urgency [8-13]. This has led to the emerging concept of a "brain-bladder control network" that adds new information to the existing knowledge of the neuroanatomy of micturition and the control of voiding (Figure 1) [14,16]. Yet, further breakthroughs are needed to improve our current insight into brain function and define factors leading to the failure of the brain to control voiding. Given recent advances in imaging methodologies, this is now possible. Let's review potential avenues.

First, we already have a simple theoretical concept of how the brain-bladder control network functions, derived from neuroanatomical and physiological studies [14] and fragmented information in about 60 functional brain imaging studies (mostly using positron emission tomography [PET] or functional magnetic resonance imaging [fMRI]). It suggests that the network may be viewed as a small number of neuronal circuits [16]. They perform sensory, motor, emotional and cognitive processing of the afferent signals arising from an increasingly filled bladder, in order to appraise them in the social context and react appropriately. In subjects with urgency, the processing appears to be impaired, since, at some volume threshold, bladder afferents are perceived as offering a threat of social embarrassment due to impending and uncontrolled leakage $[13,17,18]$. An emotional conflict like this further affects behavior and exacerbates symptoms of the disease. To ascertain how these circuits contribute to the creation of symptoms, researchers need to employ brain-scanning and urodynamic protocols that include emotional or cognitive probing tasks - for example, viewing frightening pictures or solving a puzzle. They will also need advanced methods of analysis of brain images (e.g. connectivity studies [19] and mathematical modeling [20]), which are already in use for other organ systems [21].

Second, having established "proof-of-concept" that a control network malfunction can generate the symptom of urgency, researchers will need to further investigate underlying CNS factors that might cause such a malfunction. White matter damage is a likely candidate since it may disrupt the connecting pathways of the brainbladder control network [22]. Above some unknown
Figure IA. Neuroanatomy of micturition and control of voiding, showing neuroanatomically well-established regions and projections

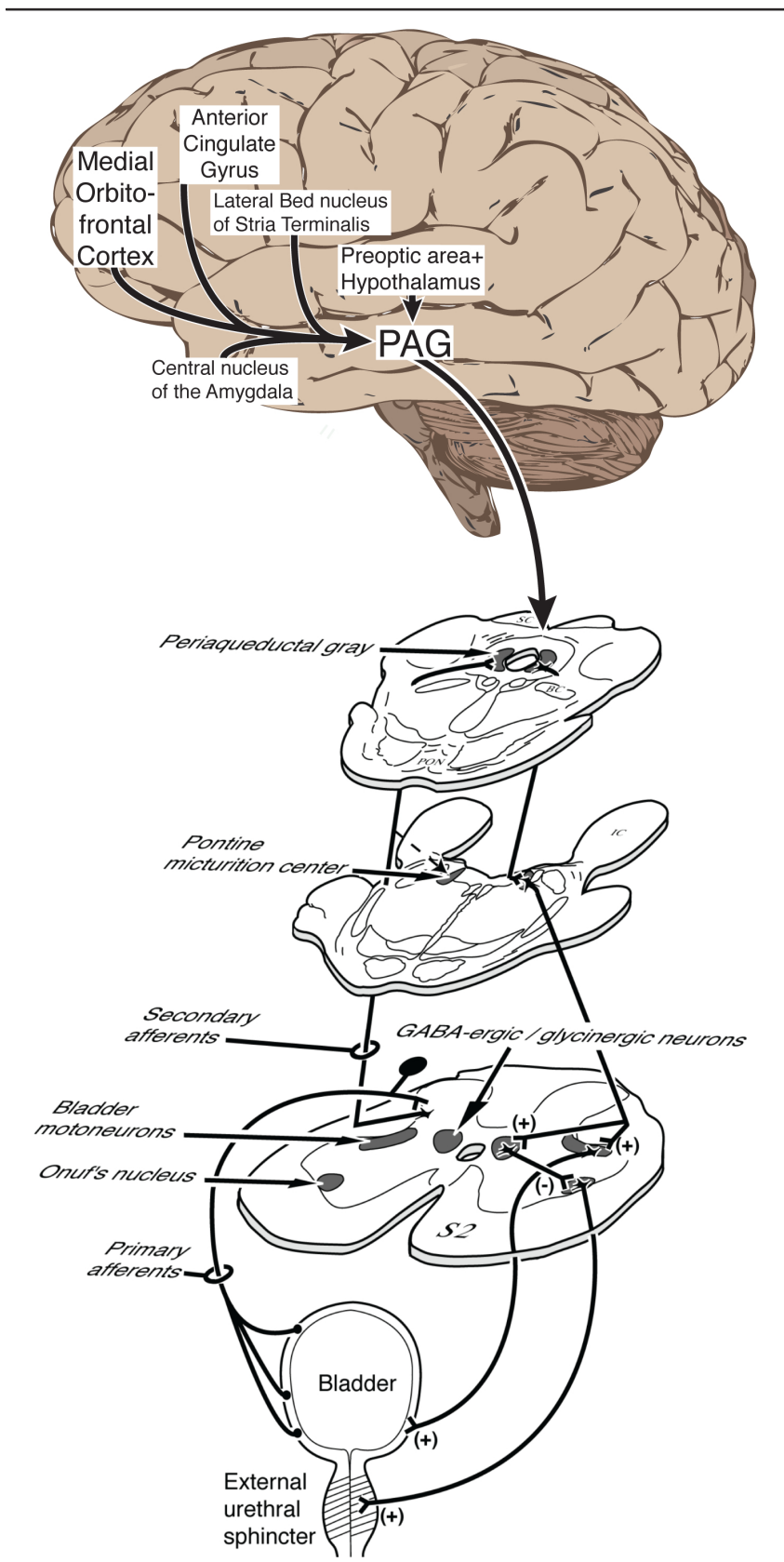

The peripheral and spinal connections support the voiding reflex, together with the pontine micturition center (PMC) and midbrain periaqueductal gray (PAG). Note that several of the brain regions shown are also registered by functional magnetic resonance (Fig. IB). They include the medial part of the prefrontal cortex and the dorsal part of the anterior cingulate gyrus, which are key areas in two cortical neural circuits postulated to control the lower urinary tract [16]. The hypothalamus and amygdala belong to a third, subcortical postulated control circuit. Brain regions that appear in

Fig. IB but not in Fig. IA (e.g. insula) represent areas of possible disagreement that remain to be resolved. 
Figure IB. Summary schematic of regional brain activity registered by functional magnetic resonance imaging (fMRI) during bladder filling experiments
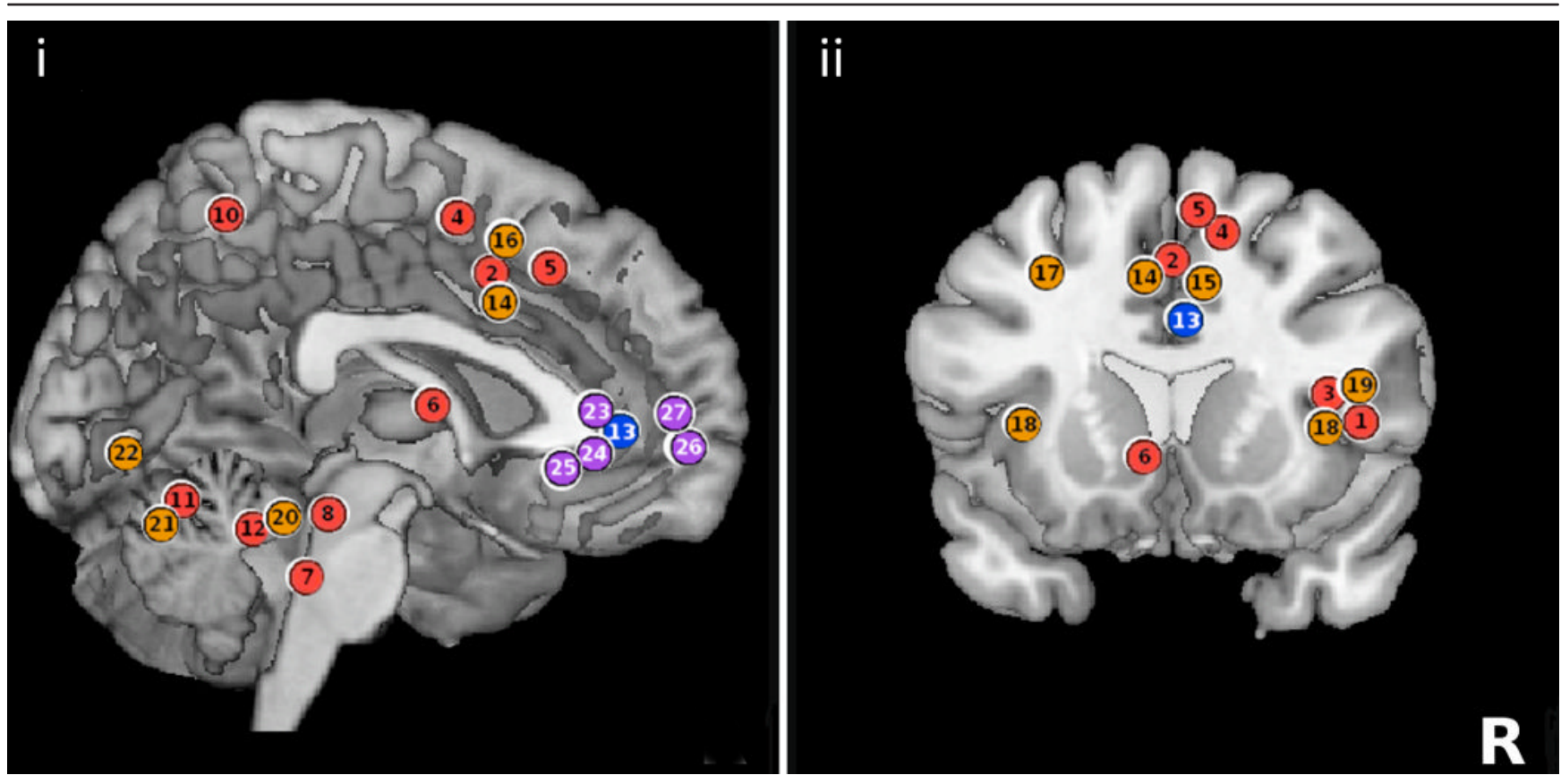

(i). Sagittal section of the brain. (ii). Coronal section of the brain. Numerals I-27 indicate areas previously published by authors Tadic and Griffiths. Color-coded circles show activation (red/orange) and deactivation (blue/purple) and are placed in approximate locations for schematic purposes. All figures are shown in neurological convention (right side on right). (With permission from Journal of Urology [16])

threshold, the disruption may be sufficient to impair control. This hypothesis is supported by large studies of older subjects that link severity of white-matter damage to decreased ability to postpone voiding and increased prevalence of urgency [23-27]. The mechanism leading to structural white-matter damage is a long-standing (hence "age-related") exposure to vascular noxa such as unregulated blood pressure [22]. Further support comes from a recent study combining functional and structural brain measurements in older females with urgency and incontinence (Figure 2) [28]. More advanced methods of assessing whitematter integrity, such as diffusion tensor imaging (DTI) [29], will be able to localize structural deficits within a specific white-matter tract [30]. In addition, DTI can show deficits in white matter that appear normal by conventional radiological methods. Deficits of this sort are more prevalent in younger subjects and may lead to urgency or incontinence with greater potential for preventive or curative intervention, if treated before irreversible whitematter damage has occurred.

Third, and most important, researchers will need to convince urologists that the brain-bladder control network is indeed related to bladder function. An obvious way would be to display, simultaneously and in real time, the activity of the bladder or urethra and the activity in the governing regions of the cerebral cortex. Thanks to functional nearinfra-red spectroscopy of the brain (fNIRS) this is now possible. fNIRS coupled with urodynamics has already demonstrated brain activity associated with detrusor overactivity (Figure 3) [31-33]. Although still in development, it offers potentially tremendous opportunities for research as it allows CNS function to be assessed inexpensively in the clinical urodynamic suite, thus allowing mass brain-bladder studies. These studies will provide critical information about how the failure of control occurs and whether control is sustained, thus enabling precise diagnosis of a possible CNS-bladder disconnect in each individual patient. Improved prognosis and better pre-treatment assessment of the probability of therapeutic response will ultimately benefit patients by streamlining disease management and reducing costs of treatment.

\section{Future directions}

At the beginning of the $21^{\text {st }}$ century, advanced brain imaging methods are poised to yield deeper insight into the forgotten role of the brain in bladder dysfunction. If successful, this approach will provide new information about bladder control that will improve diagnosis and 
Figure 2. White matter tracts and functional brain activity

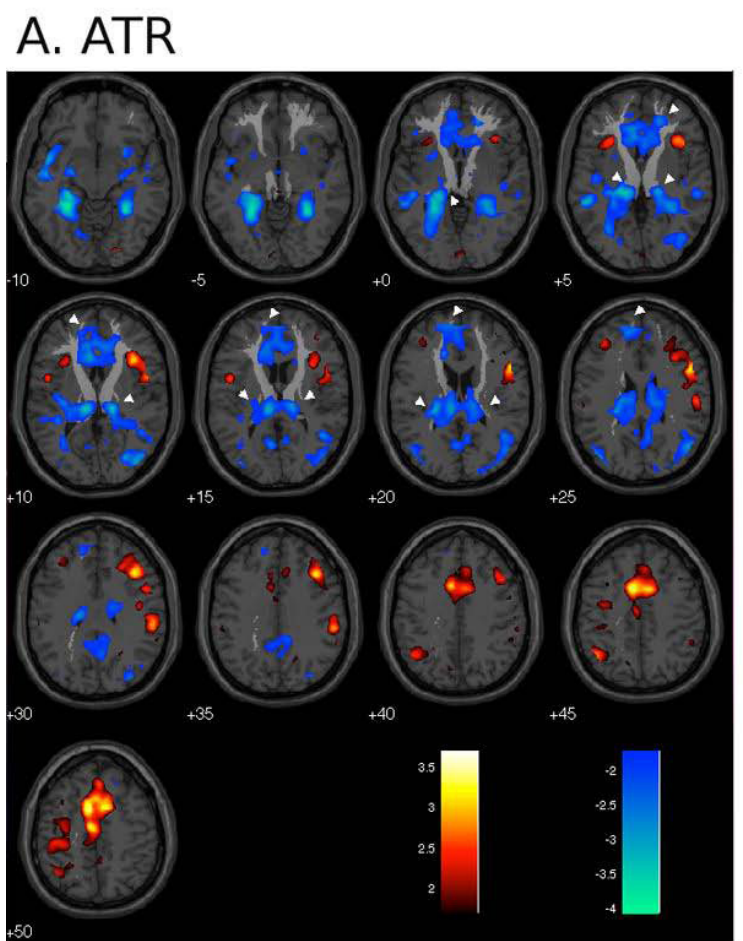

\section{B. SLF}

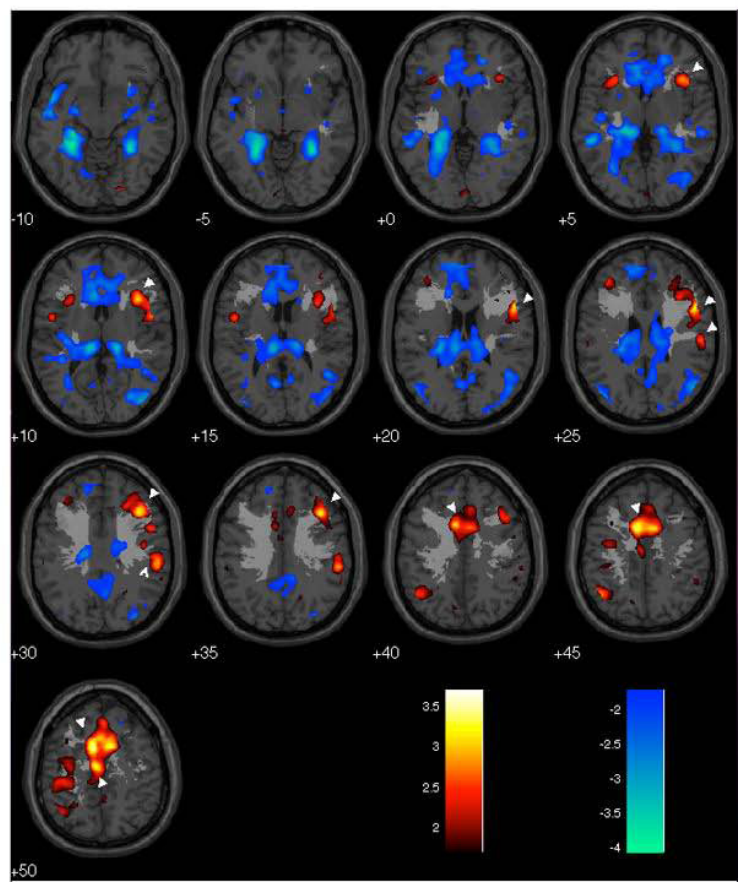

Regional brain responses to bladder filling (main effects) superimposed on selected white matter tracts; red/yellow $=$ activation, blue $=$ deactivation $(\mathrm{P}<0.0 \mathrm{l}$ uncorrected); numbers show $\mathrm{z}$-coordinates in $\mathrm{mm}$. White pointers show some of the regions where the tract appears to project to activated or deactivated areas. A. anterior thalamic radiation (ATR); B. superior longitudinal fasciculus (SLF). (with permission from Neurolmage [27])

Figure 3. fNIRS and urodynamic study

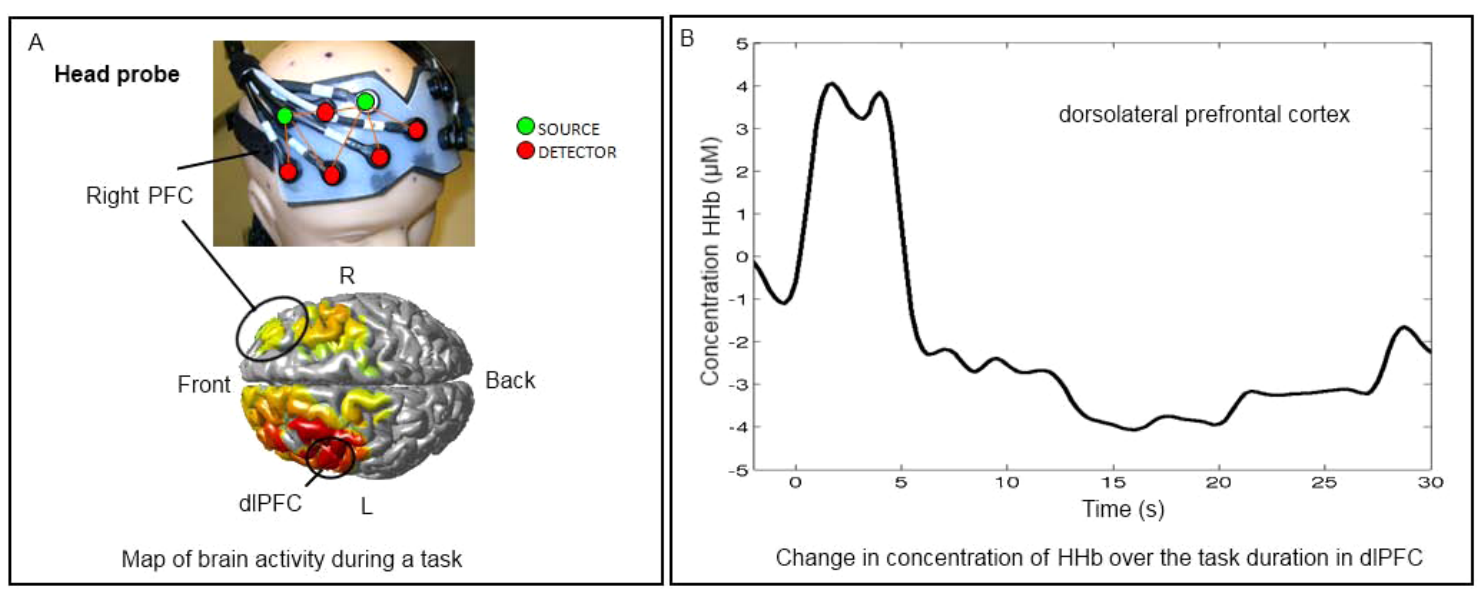

A) Upper part: Frontal section of the NIRS optical probe with a lattice of source and detector optodes, placed on a mannequin head. Lower part: Areas of significant brain activity registered during bladder filling in standard urodynamic settings (e.g. an episode of provoked detrusor overactivity as shown here) mapped onto a standard brain image. Circled area corresponds to the outlined probe. The extent and the type of activity is color coded: yellow to red - activations; green to blue - increasing deactivations. B) Graph depicting corresponding time course of change in concentration of deoxyhemoglobin in the dorsolateral prefrontal cortex during the specific task (e.g. bladder filling during urodynamics). This trace corresponds to brain activity in the encircled area on the left and is obtained in real-time from each source-detector pair during NIRS investigation. rPFC - right prefrontal cortex; dIPFC - dorsolateral prefrontal cortex; fNIRS - functional near-infrared spectroscopy. 
treatment, changing the lives of our patients and the practice of urology as we know it.

\section{Abbreviations}

CNS, central nervous system; DTI, diffuse tensor imaging; NIRS, near-infra-red spectroscopy; PET, positron emission tomography; fMRI, functional magnetic resonance imaging.

\section{Competing interests}

Dr. Tadic and Dr. Holstege have no competing interests to declare. Dr. Griffiths is a consultant for Laborie Medical Technologies.

\section{Acknowledgements}

We are especially thankful to Dr. Becky Clarkson from Geriatric Continence Research Unit at University of Pittsburgh, for the help with fNIRS data (Figure 3).

\section{References}

I. Fowler CJ, Griffiths D, de Groat WC: The neural control of micturition. Nat Rev Neurosci 2008, 9:453-66.

2. Abrams P, Cardozo L, Fall M, Griffiths D, Rosier P, Ulmsten U, van Kerrebroeck $P$, Victor $A$, Wein $A$ : The standardisation of terminology of lower urinary tract function: report from the Standardisation Sub-committee of the International Continence Society. Neurourol Urodyn 2002, 21:167-78.

3. Abrams P, Blaivas JG, Stanton S, Andersen JT: The standardisation of terminology of lower urinary tract function. Neurourology and Urodynamics 1988, 7:403-26.

4. Abrams P AK, Birder L, Brubaker L, Cardozo L, Chapple C, Cottenden A, Davila W, de Ridder D, Dmochowski R, Drake M, Dubeau C, Fry C, Hanno P, Smith JH, Herschorn S, Hosker G, Kelleher C, Koelbl H, Khoury S, Madoff R, Milsom I, Moore K, Newman D, Nitti V, Norton C, Nygaard I, Payne C, Smith A, Staskin D, Tekgul S, Thuroff J, Tubaro A, Vodusek D, Wein A, Wyndaele Jj; Members of Committees; Fourth International Consultation on Incontinence: Fourth International Consultation on Incontinence Recommendations of the International Scientific Committee: Evaluation and treatment of urinary incontinence, pelvic organ prolapse, and fecal incontinence. Neurourol Urodyn 2010, 29:213-40.

5. Andersson KE, Chapple CR, Cardozo L, Cruz F, Hashim H, Michel MC, Tannenbaum C, Wein AJ: Pharmacological treatment of overactive bladder: report from the International Consultation on Incontinence. Current Opinion in Urology 2009, 19:380-94.

6. Ouslander J: Management of Overactive Bladder. N Engl J Med 2004, 350:786-99.

7. Burgio KL, Locher JL, Goode PS, Hardin JM, McDowell BJ, Dombrowski M, Candib D: Behavioral vs drug treatment for urge urinary incontinence in older women: a randomized controlled trial. Jama 1998, 280:1995-2000.

FI000 Factor 6

Stasa Tadic 12 Sep 2012

8. Blok BF, Willemsen AT, Holstege G: A PET study on brain control of micturition in humans. Brain 1997, I20: I I I-2 I.

9. Blok BF, Sturms LM, Holstege G: Brain activation during micturition in women. Brain 1998, I $21: 2033-42$.

10. Blok BF, Holstege G: The central control of micturition and continence: implications for urology. BJU Int 1999, 83:1-6.

II. Griffiths D, Derbyshire S, Stenger A, Resnick N: Brain control of normal and overactive bladder. J Urol 2005, 174:1862-7.
12. Griffiths D, Tadic SD, Schaefer W, Resnick NM: Cerebral control of the bladder in normal and urge-incontinent women. Neurolmage 2007:doi: 10.1016/j.neuroimage.2007.1004.106I.

13. Griffiths D, Tadic SD: Bladder control, urgency, and urge incontinence: evidence from functional brain imaging. Neurourol Urodyn 2008, 27:466-74.

14. Holstege G, Griffiths D, de Wall H, Dalm E: Anatomical and physiological observations on supraspinal control of bladder and urethral sphincter muscles in the cat. J Comp Neurol 1986, 250:449-61.

15. Fowler CJ, Griffiths D: A decade of functional brain imaging applied to bladder control. Neurourol Urodyn 2010, 29:49-55.

16. Griffiths D: Use of functional imaging to monitor central control of voiding in humans. Handb Exp Pharmacol 20II, 202:8I-97.

17. Tadic SD, Griffiths D, Schaefer W, Cheng Cl, Resnick NM: Brain activity measured by functional magnetic resonance imaging is related to patient reported urgency urinary incontinence severity. J Urol 2010, 183:221-8.

18. Tadic S, Griffiths DJ, Schaefer W, Murrin A, Clarkson B, Resnick NM: Brain activity underlying impaired continence control in older women with overactive bladder. Neurourol Urodyn 201I, in press.

19. Tadic SD, Griffiths D, Schaefer W, Resnick NM: Abnormal connections in the supraspinal bladder control network in women with urge urinary incontinence. Neurolmage 2008, 39: 1647-53.

20. Stephan KE, Mattout J, David O, Friston KJ: Models of functional neuroimaging data. Curr Med Imaging Rev 2006, 2:15-34.

21. Wager TD, Waugh CE, Lindquist M, Noll DC, Frederickson BL, Taylor SF: Brain mediators of cardiovascular responses to social threat, Part I: Reciporcal dorsal and ventral subregions of the medial prefrontal cortex and heart-rate reactivity. Neurolmage 2009, 47:82I-35.

22. Schmahmann JD, SE, Eichler FS, Filley CM: Cerebral White Matter. Neuroanatomy, Clinical Neurology, and Neurobehavioral Correlates. Ann NY Acad Sci 2008:266-309.

23. Ylikoski A, Erkinjuntti T, Raininko R, Sarna S, Sulkava R, Tilvis R: White Matter Hyperintensities on MRI in the Neurologically Nondiseased Elderly: Analysis of Cohorts of Consecutive Subjects Aged 55 to 85 Years Living at Home. Stroke 1995, 26: II7|-7.

FI000 Factor 6

Stasa Tadic 12 Sep 2012

24. Poggesi APG, Chabriat H, Erkinjuntti T, Fazekas F, Verdelho A, Hennerici MLP, O'Brien J, Scheltens P, Visser MC, Crisby M, Waldemar GWA, Inzitari D, Pantoni L; Leukoaraiosis And DISability Study Group: Urinary complaints in nondisabled elderly people with age-related white matter changes: the Leukoaraiosis And DISability (LADIS) Study. J Am Geriatr Soc 2008, 56: 1638-43.

FI000 Factor 6 Stasa Tadic 12 Sep 2012

25. Kuchel GA, Moscufo N, Guttmann CR, Zeevi N, Wakefield D, Schmidt J, Dubeau CE, Wolfson L: Localization of brain white matter hyperintensities and urinary incontinence in communitydwelling older adults. J Gerontol A Biol Sci Med Sci 2009, 64:902-9.

26. Wakefield DB, Moscufo N, Guttmann CR, Kuchel GA, Kaplan RF, Pearlson G, Wolfson L: White matter hyperintensities predict functional decline in voiding, mobility, and cognition in older adults. J Am Geriatr Soc 2010, 58:275-8I.

FI000 Factor 6 Stasa Tadic 12 Sep 2012

27. Pantoni L PA, Basile AM, Pracucci G, Barkhof $F$, Chabriat $H$ Erkinjuntti T, Ferro JM, Hennerici M, O'Brien J, Schmidt R, Visser MC, Wahlund LO, Waldemar G, Wallin A, Inzitari D; LADIS Study Group: Leukoaraiosis predicts hidden global functioning impairment in nondisabled older people: the LADIS (Leukoaraiosis and 
Disability in the Elderly) Study. J Am Geriatr Soc 2006, 54: 1095-101.

28. Tadic SD, Griffiths D, Murrin A, Schaefer W, Aizenstein HJ, Resnick NM: Brain activity during bladder filling is related to white matter structural changes in older women with urinary incontinence. Neurolmage 2010, 5 I: 1294-302.

29. Assaf $Y$, Pasternak O: Diffusion Tensor Imaging (DTI)-based White Matter Mapping in Brain Research: A Review. J Mol Neurosci 2008, 34:5I-6I.

FI000 Factor 6

Stasa Tadic 12 Sep 2012

30. Smith SM, Jenkinson M, Johansen-Berg $H$, Rueckert $D$, Nichols $T E$, Mackay CE, Watkins KE, Ciccarelli O, Cader MZ, Matthews PM, Behrens TE: Tract-based spatial statistics: voxelwise analysis of multi-subject diffusion data. Neurolmage 2006, 3 I:|487-505.

FI000 Factor 6

Stasa Tadic 12 Sep 2012

3I. Matsumoto S IA, Kume H, Takeuchi T, Homma Y: Near infrared spectroscopy study of the central nervous activity during artificial changes in bladder sensation in men. Int J Urol 2009, 16:760-4.

FI000 Factor 6

Stasa Tadic 12 Sep 2012

32. Sakakibara R, Tsunoyama K, Takahashi O, Sugiyama M, Kishi M, Ogawa E, Uchiyama T, Yamamoto T, Yamanishi T, Awa Y, Yamaguchi C: Real-time measurement of oxyhemoglobin concentration changes in the frontal micturition area: an fNIRS study. Neurourol Urodyn 2010, 29:757-64.

FI000 Factor 6 Stasa Tadic 12 Sep 2012

33. Farag FF, Martens FM, D'Hauwers KW, Feitz WF, Heesakkers JP: Near-Infrared Spectroscopy: A Novel, Noninvasive, Diagnostic Method for Detrusor Overactivity in Patients with Overactive Bladder Symptoms - A Preliminary and Experimental Study. Eur Urol 20I I, 59:757-62.

FI000 Factor 6

Stasa Tadic 12 Sep 2012 